\title{
Aplicabilidade da Terapia Fotodinâmica na Odontopediatria
}

\author{
Applicability of Photodynamic Therapy in Pediatric Dentistry \\ Aplicabilidad de la Terapia Fotodinámica en la Odontopediatría \\ Thamyres Maria Silva SIMÕES ${ }^{1}$ \\ Ana Luzia Araújo BATISTA ${ }^{\mathbf{1}}$ \\ José de Alencar FERNANDES NETO ${ }^{1}$ \\ Maria Helena Chaves de Vasconcelos CATÃO ${ }^{2}$ \\ ${ }^{2}$ Professora Doutora em Odontologia, Departamento de Odontologia, Universidade Estadual da Paraíba, UEPB, 58429-500, Campina Grande-PB, Brasil
}

${ }^{1}$ Programa de Pós-Graduação em Odontologia, Departamento de Odontologia, Universidade Estadual da Paraíba, UEPB, 58429-500, Campina Grande-PB, Brasil

\begin{abstract}
Resumo
Objetivo: Avaliar através de uma revisão de literatura a aplicabilidade da terapia fotodinâmica (TFD) na Odontopediatria. Material e método: O levantamento literário para esta pesquisa foi realizado no período de dezembro de 2018 a janeiro de 2019, através de buscas em publicações científicas indexadas nas bases de dados Scielo e Medline/PubMed, utilizando isoladamente ou em associação as palavras-chaves "Photochemotherapy", "Dental caries", "Photodynamic therapy", "Children”. Resultados: Após a busca sistematizada foram encontrados 143 artigos, desses, 137 foram excluídos por não atenderem aos critérios de inclusão, 5 artigos foram pré-selecionados, sendo 2 repetidos. Ao final, 3 artigos foram incluídos nessa revisão. Conclusão: Esse estudo incorporou as principais aplicabilidades da TFD na Odontopediatria: no tratamento da cárie dentária e como terapia complementar ao tratamento endodôntico convencional, entretanto o efeito antimicrobiano desta modalidade terapêutica ainda apresenta limitações, devido à falta de padronização nos estudos.
\end{abstract}

Descritores: Odontopediatria; Fotoquimioterapia; Terapia com Luz de Baixa Intensidade.

\section{Abstract}

Objective: To evaluate, through a literature review, the applicability of photodynamic therapy in pediatric dentistry. Material and method: The literature survey for this research was carried out from December 2018 to January 2019, through searches in scientific publications indexed in the Scielo and Medline / PubMed databases, using the keywords " Photochemotherapy "," Dental caries "," Photodynamic therapy "," Children ". Results: After the systematized search, 143 articles were found, of which 137 were excluded because they did not meet the inclusion criteria; 5 articles were pre-selected, of which 2 were repeated. At the end, 3 articles were included in this review. Conclusion: This study incorporated the main applications of PDT in pediatric dentistry: in the treatment of dental caries and as a complementary therapy to conventional endodontic treatment. However, the antimicrobial effect of this modality still presents limitations due to lack of standardization in the studies.

Descriptors: Pediatric Dentistry; Photochemotherapy; Low-Level Light Therapy.

\section{Resumen}

Objetivo: Evaluar a través de una revisión de literatura la aplicabilidad de la terapia fotodinámica en la odontopediatría. Material y método: El levantamiento literario para esta investigación fue realizado en el período de diciembre de 2018 a enero de 2019, a través de búsquedas en publicaciones científicas indexadas en las bases de datos Scielo y Medline / PubMed, utilizando aisladamente o en asociación las palabras clave " "Photochemotherapy", "Dental caries", "Photodynamic therapy", "Children". Resultados: Después de la búsqueda sistematizada, fueron encontrados 143 artículos, de los cuales 137 fueron excluidos por no atender a los criterios de inclusión, 5 artículos fueron preseleccionados, siendo 2 repetidos. Al final, 3 artículos se incluyeron en esta revisión. Conclusión: Este estudio incorporó las principales aplicabilidades de la TFD en la odontopediatría: en el tratamiento de la caries dental y como terapia complementaria al tratamiento endodóntico convencional, sin embargo el efecto antimicrobiano de esta modalidad terapéutica todavía presenta limitaciones, debido a la falta de estandarización en los estudios.

Descriptores: Odontología Pediátrica; Fotoquimoterapia;Terapia por Luz de Baja Intesidad.

INTRODUÇÃO

A cárie dentária é uma patologia de caráter multifatorial, resultante do desequilíbrio entre os processos de desmineralização e remineralização do esmalte dentário ocasionado por ácidos produzidos pelos microrganismos presentes no biofilme dental. Por ser a doença crônica mais comum na infância, a cárie dentária revela-se como um grande desafio para a saúde pública em nível mundial e requer cuidados dentários especiais e técnicas de tratamento inovadoras que priorizem a mínima intervenção ${ }^{1,2}$.

Segundo o Ministério da Saúde, em seu último levantamento de saúde bucal, o índice de cárie em crianças aos 5 anos de idade está acima do máximo recomendado pela Organização Mundial de Saúde (OMS), menor que 3, e o componente cariado continua o mais expressivo, quando comparado com os achados anteriores ${ }^{3}$.

Múltiplos fatores podem influenciar o início e progressão da cárie dentária, como o fluxo e a composição salivar, bactérias cariogênicas, exposição inadequada ao flúor, componentes imunológicos e fatores genéticos. No entanto, o estilo de vida, comportamento, higiene, hábitos alimentares, nível social e fatores sociodemográficos, também contribuem para a evolução da doença ${ }^{4}$.

No seu processo dinâmico, após a desmineralização do esmalte, a cárie pode progredir lentamente em direção à dentina; sua camada externa, conhecida como dentina infectada, caracterizada por tecido amolecido com um grande número de bactérias. A camada mais interna, conhecida como dentina afetada, contaminada por menos bactérias, é geralmente submetida ao processo de remineralização. A distinção clínica dessas duas regiões é extremamente difícil, e geralmente os métodos convencionais que envolvem a remoção deste tecido, podem resultar em exposição pulpar de lesões profundas de cárie ${ }^{5}$.

A redução de microrganismos patogênicos da superfície dental é um dos principais fatores envolvidos na prevenção e no controle da cárie dentária6. Em virtude da possibilidade de aplicação tópica e de seu efeito localizado, a utilização da Terapia Fotodinâmica (TFD) para o tratamento de 
lesões de cárie tem sido bastante discutida na literatura $^{7-10}$.

Historicamente a ação antimicrobiana da TFD começou a ser estudada sobre bactérias cariogênicas em $1993^{11}$. Estudos in vitro já foram conduzidos utilizando a TFD com sucesso para inibição de bactérias gram-positivas, como Streptococcus Sorbrinus, Streptococcus mutans e Streptococcus Sanguinis, que desempenham papel importante na etiologia da cárie dentária ${ }^{12,13}$.

A TFD baseia-se na aplicação tópica ou sistêmica de um corante não tóxico e fotossensível, seguida da irradiação com baixas doses de luz de comprimento de onda adequado, resultando na produção de radicais livres, oxigênio singlete e outras espécies reativas de oxigênio, que têm um efeito tóxico nas células bacterianas, levando à morte celular sem causar danos ao hospedeiro ${ }^{14-18}$.

As vantagens desse método incluem a eliminação de bactérias em um curto espaço de tempo, ausência de lesão dos tecidos adjacentes, acesso a áreas com anatomia complexa, baixo risco de bacteremia em pacientes imunocomprometidos e alta reprodutibilidade ${ }^{19,20}$, sendo a TFD uma terapia antibacteriana alternativa para doenças relacionadas à placa, como a cárie dentária em crianças ${ }^{8}$.

Nesse contexto, o presente artigo tem como objetivo avaliar através de uma revisão de literatura a aplicabilidade da TFD na Odontopediatria.

\section{MATERIAL E MÉTODO}

Foi realizada pesquisa eletrônica, na qual foram levantados estudos, obedecendo aos seguintes critérios de inclusão: artigos científicos, compreendidos entre o período de 2013 a 2018, que tratassem sobre a utilização da TFD no tratamento da cárie dentária em crianças. Os artigos anteriores a 2013, revisões de literatura, publicações de iniciação científica, artigos com direcionamento médico e cirúrgico foram excluídos. $\mathrm{O}$ dados foram levantados no período de dezembro de 2018 a janeiro de 2019, através de buscas em publicações científicas indexadas nas bases de dados Scielo e Medline/PubMed, utilizando isoladamente ou em associação as palavras-chaves "Photochemotherapy", "Dental caries", "Photodynamic therapy", "Children".

\section{RESULTADOS}

Após a busca sistematizada, foram encontrados 143 artigos com as palavras-chaves utilizadas nessa pesquisa. Desses, 137 foram excluídos por não atenderem aos critérios de inclusão descritos na metodologia, 5 artigos foram préselecionados, sendo 2 repetidos. Ao final, 3 artigos foram incluídos nessa revisão. A faixa etária dos pacientes nesses estudos foi entre 3 e 6 anos, sendo eles a maioria do sexo masculino. A caracterização dos estudos quanto aos objetivos, protocolos utilizados e suas conclusões estão apresentados na Tabela 1 .

Tabela 1. Caracterização dos estudos quanto aos objetivos, protocolos de tratamento utilizados e conclusões

\begin{tabular}{|c|c|c|c|}
\hline Autor/Ano & Objetivo & Detalhamento do estudo & Conclusão \\
\hline $\begin{array}{l}\text { Bargrizan } \\
\text { et al. } 7\end{array}$ & $\begin{array}{c}\text { Avaliar o efeito } \\
\text { antibacteriano da } \\
\text { TFD com azul de } \\
\text { toluidina (TBO) e } \\
\text { laser de diodo em } \\
\text { Streptococcus mutans } \\
\text { em crianças com } 5 \text { a } 6 \\
\text { anos com cárie } \\
\text { precoce na primeira } \\
\text { infância }\end{array}$ & $\begin{array}{c}56 \text { crianças } \\
\text { 5 - } 6 \text { anos de idade } \\
\text { Grupo 1: TBO } 15 \text { mL de TBO } \\
\text { (o,1mg/mL) mantendo-se na } \\
\text { boca por } 15 \text { minutos e sendo } \\
\text { depois descartada } \\
\text { Grupo 2: laser }(\AA=633 \mathrm{~nm} ; \\
\text { 20mW;6J/cm2;InGA ALP, } \\
\text { Mustang 2000, Rússia) } \\
\text { Grupo 3: TBO + Laser } \\
\text { Grupo 4: Controle }\end{array}$ & $\begin{array}{c}\text { A eficácia } \\
\text { antimicrobiana do } \\
\text { TBO + Laser foi } \\
\text { maior que Laser e } \\
\text { TBO } \\
\text { isoladamente. } \\
\text { Durabilidade do } \\
\text { tratamento } \\
\text { aumentou com } \\
\text { terapia de dose } \\
\text { dupla. Esta } \\
\text { modalidade pode } \\
\text { ser usada para } \\
\text { diminuir a } \\
\text { contagem de } \\
\text { colônias de } \\
\text { Streptococcus } \\
\text { mutans em } \\
\text { crianças com cárie } \\
\text { precoce na } \\
\text { primeira infância }\end{array}$ \\
\hline Fekrazad et al..$^{8}$ & $\begin{array}{l}\text { Avaliar os efeitos da } \\
\text { TFD antimicrobiana } \\
\text { na redução de } \\
\text { Streptococcus mutans } \\
\text { em crianças com cárie } \\
\text { precoce na criança }\end{array}$ & $\begin{array}{c}23 \text { crianças } \\
3-6 \text { anos de idade } \\
\text { TFD: } \\
\text { TBO: } 10 \mathrm{oml}(\mathrm{o}, 1 \mathrm{mg} / \mathrm{mL}) \text { por } 1 \\
\text { minuto } \\
+ \\
\text { LED }(\AA=63 \mathrm{onm} ; \\
\text { 20omW;300J/cm2;150s; } \\
\text { FotoSan; CMSDental; } \\
\text { Dinamarca) }\end{array}$ & $\begin{array}{c}\text { TFD } \\
\text { antimicrobiana } \\
\text { parece ser } \\
\text { eficiente para } \\
\text { reduzir } \\
\text { Streptococcus } \\
\text { mutans } \\
\text { imediatamente } \\
\text { após o tratamento } \\
\text { em crianças na } \\
\text { primeira infância. } \\
\text { Necessário avaliar } \\
\text { diferentes doses e } \\
\text { frequência de } \\
\text { irradiação em } \\
\text { combinação com a } \\
\text { restauração de } \\
\text { dentes cariados } \\
\text { para encontrar } \\
\text { resultados mais } \\
\text { duradouros }\end{array}$ \\
\hline Sant'Anna ${ }^{21}$ & $\begin{array}{l}\text { Relatar tratamento } \\
\text { endodôntico de dente } \\
\text { decíduo após } \\
\text { traumatismo dentário } \\
\text { em criança com } \\
\text { diabetes tipo I usando } \\
\text { TFD antimicrobiana }\end{array}$ & $\begin{array}{c}\text { Criança com } 5 \text { anos de idade } \\
\text { TFD } \\
\text { Azul de Metileno (AM) } \\
\text { 5omg/mL por } 3 \text { a } 5 \text { minutos } \\
+ \\
\text { Laser } \\
(\AA=660 \mathrm{onm} ; 40 \mathrm{~J} / \mathrm{cm} 2 ; \text { Therapy } \\
\text { XT-DMC; São Carlos-Brasil) }\end{array}$ & $\begin{array}{c}\text { TFD } \\
\text { antimicrobiana } \\
\text { proporcionou } \\
\text { excelente } \\
\text { prognóstico com } \\
\text { substancial } \\
\text { redução } \\
\text { bacteriana e } \\
\text { interessante } \\
\text { relação custo/ } \\
\text { benefício na } \\
\text { Odontopediatria }\end{array}$ \\
\hline
\end{tabular}

DISCUSSÃO

A TFD é um tratamento que engloba a ação simultânea de uma fonte de luz e de um agente fotossensibilizante, na presença do oxigênio dos tecidos. A combinação destes componentes produz espécies reativas de oxigénio e conduz à destruição das células alvo. Há grande interesse no efeito antimicrobiano desta terapia, uma vez que é possível eliminar grande número de bactérias gram-positivas e gram-negativas orais ${ }^{18,22}$.

A maioria das espécies bacterianas não apresenta componentes fotossensíveis, o que justifica a utilização de fotossensibilizador que interaja com determinado comprimento de onda e inicie a formação de radicais livres ${ }^{23}$. Dentre os fotossensibilizantes utilizados no tratamento de infecções bucais, os derivados das fenotiazinas, o azul de toluidina e o azul de metileno foram os mais estudados nas pesquisas ${ }^{24}$

Bargrizan et al. $^{7}$ e Fekrazad et al. ${ }^{8}$, demonstraram uma redução significativa na viabilidade de $S$. mutans em crianças com cárie precoce após a TFD com a utilização do TBO como 
fotossensibilizador, estando em consonância com os achados de Rolim et al. ${ }^{22}$, no seu estudo in vitro. Ao examinarem a atividade antimicrobiana de vários fotossensibilizadores, estes autores observaram uma redução de $99,9 \%$ de $S$. mutans, após a utilização do TBO ativado por LED $(\lambda=636 \mathrm{~nm})$, isso ocorre devido as propriedades físico-químicas e características hidrofílicas deste fotossensibilizador, que permitem a passagem livre através da membrana bacteriana e, consequentemente, a atração pelo potencial de carga negativa da mitocôndria, o que permite ação direta sobre essa organela ${ }^{22,25}$.

No estudo de Fekrazad et al. ${ }^{8}$ foi utilizado o LED como fonte de luz para ativação do agente fotossensiblizante. Para Paulino et al. ${ }^{26}$, qualquer fonte de luz que tenha características espectrais apropriadas pode ser utilizada em terapia fotodinâmica, desde que esta seja centrada na região do espectro na qual possa excitar o agente fotossensibilizante, para que haja transferência de energia e ocorra a reação fotodinâmica.

Os LEDs são fontes alternativas de luz e diferem do laser apresentando feixes divergentes, baixo componente térmico e luz monocromática ${ }^{27}$. Ao compararmos os resultados deste estudo com pesquisas que utilizaram lasers de luz branca ou convencional $^{7,21}$, o LED apresentou resultados tão positivos quanto as demais fontes de luz.

A TFD é uma abordagem promissora também como terapia adjuvante ao tratamento endodôntico convencional, na eliminação de microrganismos persistentes após o preparo químicomecânico $^{28}$. Diversos estudos têm investigado a atividade da TFD em bactérias relacionadas a doenças pulpares, com uma redução de $70 \%$ das bactérias viáveis ${ }^{28-30}$, resultados semelhantes foram demonstrados no estudo de Sant'Anna ${ }^{21}$. Neste estudo, observou-se uma substancial redução bacteriana ao utilizar a TFD com azul de metileno como fotossenbilizador, além de uma interessante relação tempo-custo-benefício ao utilizar esta terapia, já que o uso da TFD permite uma sessão de tratamento mais curta, essencial na Odontopediatria, o que pode aumentar o sucesso do tratamento endodôntico.

\section{CONCLUSÃO}

De modo geral, esse estudo incorporou as principais aplicabilidades da TFD na odontopediatria: no tratamento da cárie dentária, através da eliminação dos principais microrganismos responsáveis pela sua progressão, como o $S$. mutans, e como terapia complementar ao tratamento endodôntico convencional, contribuindo na redução da resistência microbiana após o preparo químico-mecânico. A TFD se apresenta como excelente opção de tratamento, já que é considerado um tipo de procedimento terapêutico seguro, minimamente invasivo, preservando estrutura dental hígida e oferecendo ao organismo condições adequadas de recuperação. Apesar dos inúmeros estudos e resultados promissores, o efeito antimicrobiano desta modalidade terapêutica ainda apresenta limitações, devido à falta de padronização nos estudos.

\section{REFERÊNCIAS}

1. Lopes TR, Almeida ABD, Moreira RDO, Carvalho AAH, Garcia FDM, Rocha CM et al. Determinantes sociais e biológicos da cárie dentária na infância: Uma experiência interdisciplinar no PET Saúde-UFJF. Rev APS. 2015;18(1):30-8.

2. Steiner-Oliveira C, Longo PL, Aranha AC, Ramalho KM, Mayer MP, de Paula Eduardo C. Avaliação in vivo randomizada da quimioterapia antimicrobiana fotodinâmica na dentina cariada de dentes decíduos. J Biomed Opt. 2015; 20(10):108003.

3. Brasil. Ministério da Saúde. Projeto SBBrasil 2010. [Acesso Janeiro/2019]. Available from: http://dab.saude.gov.br/CNSB/sbbrasil/

4. Borges TS, Schwanke NL, Reuter CP, Kraether Neto L, Burgos MS. Fatores associados à cárie: pesquisa de estudantes do sul do Brasil. Rev Paul Pediatr. 2016;34(4):489-494.

5. Lima JP, Sampaio MAM, Borges FM, Teixeira AH, Steiner-Oliveira C, Nobre dos Santos $M$ et al. Avaliação do efeito antimicrobiano da terapia antimicrobiana fotodinâmica em modelo in situ de cárie dentinária. Eur J Oral Sci. 2009;117(5):568-74.

6. Zanin, I.C.J; Brugnera Jr, A; Gonçalves, R. B. Application of the photodinamic therapy in bacterial decontamination. Rev Assoc Paul Cir Dent. 2002; 56(supl):7-11.

7. Bargrizan M, Fekrazad R, Goudarzi N, Goudarzi $\mathrm{N}$. Effects of antibacterial photodynamic therapy on salivary mutans streptococci in 5- to 6- yearolds with severe early childhood caries. Lasers Med Sci. 2019;34(3):433-40.

8. Fekrazad R, Seraj B, Chiniforush N, Rokouei M, Mousavi N, Ghadimi S. Effect of antimicrobial photodynamic therapy on the counts of salivary streptococcus mutans in children with severe early childhood caries. Photodiagnosis Photodyn Ther.2017;18:319-322.

9. Perussi JR. Inativação fotodinâmica de microrganismos. Quim Nova 2007;30(4):988-94.

10.Zanin ICJ, Gonçalves RB, Brugnera JRA, Hope CK, Pratten J. Susceptibility of Streptococcus mutans biofilms to photodynamic therapy: an in vitro study. J Antimicrob Chemother. 2005; 56(2):324-30.

11. Burns T, Wilson M, Pearson GJ. Sensitisation of cariogenic bacteria to killing by light from a helium-neon laser. J Med Microbiol. 1993;38(6):401-5.

12. Takasaki AA, Aoki A, Mizutani K, Schwarz F, 
Sculean A, Wang CY et al. Application of antimicrobial photodynamic therapy in periodontal and peri-implant diseases, Periodontol. 2009;51:109-40.

13. Lima JPM, Sampaio de Melo MA, Borges FMC, Teixeira AH, Steiner-Oliveira C, Santos MN et al. Evaluation of the antimicrobial effect of photodynamic antimicrobial therapy in an in situ model of dentine caries. Eur J Oral Sci. 2009;117(5):568-74.

14. Tavares A, Carvalho CMB, Faustino MA, Neves MGPMS, Tomé JPC, Tomé AC et al. Antimicrobial photodynamic therapy: st of bacterial recovery viability and potential development of resistance after treatment. Mar Drugs. 2010;8(1):91-105.

15. Goulart RC, Bolean M, Paulino TP, Thedei Jr G, Souza SLS, Tedesco AC et al. Photodynamic therapy in planktonic and biofilm cultures of Aggregatibacter actinomycetemcomitans. Photomed Laser Surg. 2010;28(Suppl 1):S53-60.

16. Rajesh S, Koshi E, Philip K, Mohan A. Antimicrobial photodynamic therapy: an overview. J Indian Soc Periodontol. 2011; 15(4):323-27.

17. Mang TS, Tayal DP, Baier R. Photodynamic therapy as an alternative treatment for disinfection of bacteria in oral biofilms. Lasers Surg Med. 2012;44(7):588-96.

18. Catão MHV, Lima RF, Almeida CM, Nascimento LV. O efeito antimicrobiano da terapia fotodinâmica sobre a dentina cariada. UNOPAR Cient Ciênc Biol Saúde. 2014;16(3):245-49.

19. Hope CK, Wilson M. Induction of lethal photosensitization in biofilms using a confocal scanning laser as the excitation source. J Antimicrob Chemother. 2006;57(6):1227-30.

20. Garcez A, Ribeiro MS, Tegos GP, Nunez SC, Jorge AOC, Hamblin MR. Antimicrobial photodynamic therapy combined with conventional endodontic treatment to eliminate root canal biofilm infection. Lasers Surg Med. 2007;39(1):59-66.

21. Sant'Anna G. Photodynamic therapy for the endodontic treatment of a traumatic primary tooth in a diabetic pediatric patient. J Dent Res Dent Clin Dent Prospects. 2014;8(1):56-60.

22. Rolim JPML, Melo MA, Guedes SF, Albuquerque-Filho FB, Souza JR, Nogueira NA et al. The antimicrobial activity of photodynamic therapy against Streptococcus mutans using different photosensitizers. J Photochem Photobiol B. 2012;106:40-6.

23. Wilson M. Bacterial biofilms and human diseae. Sci Prog. 2001;84(3):235-54.
24.Longo JPF, Azevedo RB. Efeito da terapia fotodinâmica mediada pelo azul de metileno sobre bactérias cariogênicas. Rev Clín Pesq Odontol. 2010;6(3):249-57.

25. Nagata JY, Hioka N, Kimura E, Batistela VR, Terada RSS, Graciano AX et al. Antibacterial photodynamic therapy for dental caries: evaluation of the photosensitizers used and light source properties. Photodiagnosis Photodyn Ther. 2012;9(2):122-31.

26. Paulino TP, Ribeiro KF, Thedei Jr G, Tedesco AC, Ciancaglini P. Use of hand held photopolymerizer to photoinactivate Streptococcus mutans. Arch Oral Biol. 2005;50(3):353-59.

27. Santin GC, Oliveira DSB, Galo R, Borsatto MC, Corona SAM. Antimicrobial photodynamic therapy and dental plaque: a systematic review of the literature. ScientificWorldJournal. 2014; 2014: 824538.

28. Fimple JL, Fontana CR, Foschi F, Ruggiero K, Song X, Pagonis TC et al. Photodynamic treatment of endodontic polymicrobial infection in vitro. J Endod. 2008;34(6):728-34.

29. Garcez AS, Nuñez SC, Hamblin MR, Ribeiro MS. Antimicrobial effects of photodynamic therapy on patients with necrotic pulps and periapical lesion. J Endod. 2008;34(2):138-42.

30. Garcez AS, Nuñez SC, Sr. Hamblim, Suzuki H, Ribeiro MS. Photodynamic therapy associated with conventional endodontic treatment in patients with Antibiotic-Resistant Microflora: A Preliminary Report. J Endod. 2010;36(9):1463-66.

\section{CONFLITO DE INTERESSES}

Os autores declaram não haver conflitos de interesse.

AUTOR PARA CORRESPONDENCIA

Maria Helena Chaves de Vasconcelos Catão

mhcvcatao@gmail.com

Submetido em 27/02/2019

Aceito em 24/05/2019 